\title{
6 ¿Considerando la dependencia que de la inversión tiene el crecimiento, cual es el perfil ideal de un ambiente para incrementar la inversión?
}

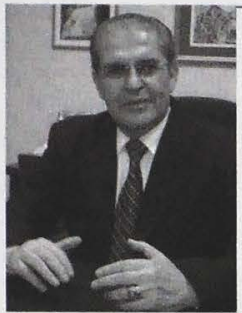

Rafael Rodríguez Loucel, UTEC
Aprovecho la oportunidad para enfarizar la necesidad que se tiene de armonizar los esfueros de estabilización que regulan la demanda con los de reactivación de oferta. Habría que destinar, entonces, los recursos internos y externos a "invertir" y "producir" que es lo que en definitiva podría evitar más presiones inflacionarias, más endeudamiento gubernamental, más déficit fiscal y en definitiva propiciar un crecimiento económico sostenido con estabilidad financiera.

Acciones concretas para propiciar un clima propicio de inversiones son la ley de competencia, la seguridad ciudadana, la seguridad jurídica, la garantía de los derechos humanos, igualdad de oportunidades, apoyo decidido a la integración regional, un crecimiento equilibrado devolviéndole la rentabilidad a la agricultura, la instauración de un Estado de Derecho, continuar con los esfuerzos de desarrollo de infraestructura vial y portuaria e implementar mecanismos preventivos correctivos para la erradicación de la violencia.

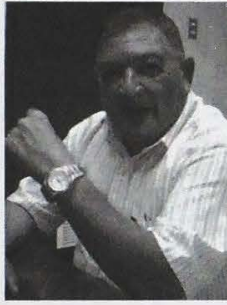

Jorge Barraza lbarra, UTEC
En estos últimos tiempos he leído muchas opiniones sobre la necesidad de garantizar las reglas de juego para promover las inversiones, del clima de seguridad ciudadana, del Estado de Derecho, del papel negativo de los sindicatos, de mantener la competitividad a base de salarios reducidos. Todo cuenta, lo anterior $y$ otras cosas más, sin embargo en la teoría económica, en los libros recientes de texto, los autores siguen insistiendo que la inversión se produce cuando las empresas obtienen tasas de rentabilidad superiores a sus costes de inversión. "Esta sencilla afirmación contiene los tres elementos esenciales para comprender la inversión: los ingresos, los costes y las expectativas."

En El Salvador se está apostando todo a una inversión extranjera que no viene, pese a todos los privilegios que se le of recen. Es difícil de explicar porqué los empresarios nacionales no invierten, y porqué las grandes empresas fijan sus expectativas en mercados extranjeros. ¿Será que no creen en su propio pais? Creo que es importante hacer conciencia que el desarrollo del país deberá estar soportado por el ahorro interno y la capacidad de compra del mercado interno.

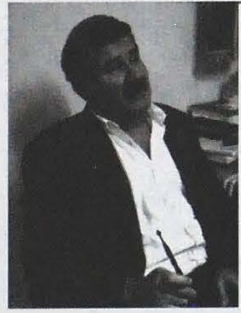

Roberto Rublo, FUNDE
La creación de fondos a través de más impuestos siempre será insuficiente, por lo que se necesita fondos más gruesos que pueden venir de la inversión externa, inversionistas privados, ingresos que pueden venir de otras modalidades. Por ejemplo, tazar el crédito como se hace con la gasolina, poner un impuesto de colaboración, llamémosle así, entre el banco que otorga el crédito y el que lo recibe a partir de cierto monto.

Para atraer inversionistas es necesario que la inversión pública esté orientada a la producción, como capital semilla para atraer otros fondos, pueden meterse fondos de las alcaldías que pueden compartirse, hay muchas cosas que se pueden hacer para buscar estos fondos y darle una orientación productiva. Tal vez así, apostándole a actividades muy específicas, a proyectos tanto grandes como medianos, reacrivar zonas enteras, generar más empleo. Creo que por ahí más o menos hay una salida. 


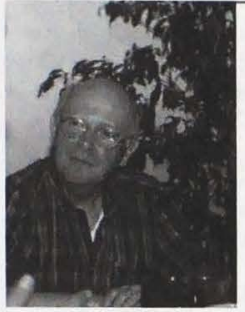

Héctor Dada Hirezi, Dipurado COU
Se nos viene diciendo desde hace un decenio que El Salvador tiene las condiciones para ser un destino privilegiado de la inversión extranjera. Así se han justificado las medidas de ajuste que se han aplicado. Pero ella no viene al ritmo esperado, y en la práctica es menos que la que se realiza en países similares que no han tomado tan ortodoxamente el fundamentalismo del mercado. La carencia de una estrategia definida de desarrollo, que defina la apuesta básica del país, es un obstáculo para inversores nacionales o extranjeros.

La inversión requiere visiones claras que den cierta seguridad del mantenimiento de las reglas y las apuestas hacia el futuro, la neutralidad del ejercicio de la función pública frente a intereses de grupos empresariales específicos (que no es el caso de nuestro pais, en el que se ejerce con sentido patrimonial la función pública), seguridad ju rídica que implica respero a la inscitucionalidad, seguridad ciudadana, eficiencia en la prestación de servicios de los organismos estatales, mano de obra eficiente y calificada.

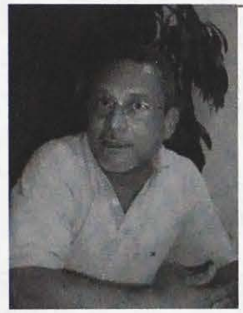

Carlos Briones, FLACSO
El Estado necesita invertir en la educación y en la salud, necesita dinero y por tanto, necesita disponibilidad fiscal para que crear el punto de quiebre para transformar cierras condiciones de los factores productivos, y obtener más capital humano y físico a través de las inversiones públicas, para que los oper adores o los agentes privados empiecen a operar en mejores condiciones. Pero ese equilibrio es difícil, para lograrlo, en primer lugar, debe mejorarse la eficiencia en la recaudación tributaria, cobrar más efectivamente porque no puede negarse que en el pais hay una evasión fiscal.

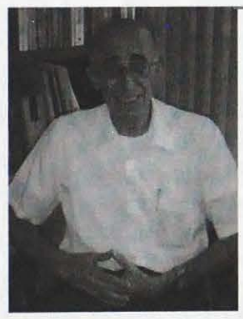

Javier Iblsate, UCA
Lo primero es observar que en los últimos años la inversión privada apenas se mueve, al mismo ciempo que la inversión pública (posterremoto 2001) se ve paralizada por la "espada de Damocles" de la desuda externa. La misma Asociación Nacional de la Empresa Privada (ANEP), que en su 11 Enade (2001) rinde pleitesía al "Marco Filosófico Doctrinario" de la economía de libre mercado (p. 10), reconoce ( $\mathrm{p}$ : $14 \mathrm{La}$ Educación) que estamos muy atrasados en el conocimiento y aplicación de las nuevas tecnologías, al darse un divorcio entre Estado, empresas y universidades.

La tecnología competitiva no está motivando la inversión, ni tampoco la demanda agregada en estancamiento. No le echemos la culpa simplemente a la ralentización de la economía mundial. Con la dolarización han bajado las tasas de interésy, sin embargo, no se está activando la inversión interna. Por otra parte, con los sonados casos de corrupción y su impunidad, la burocracia de que se quejan las empresas, la delincuencia creciente y la impunidad... no es el mejor escenario para un catalizador de la inversión. Es triste decirlo. 